\title{
Contributing to Sustainable Healthcare Systems with Case Theory
}

\author{
Evert Gummesson ${ }^{1}$, Debora Sarno ${ }^{2}$, Luca Carrubbo ${ }^{3} \&$ Carlo Sirianni $^{4}$ \\ ${ }^{1}$ Stockholm Business School, Stockholm, Sweden \\ ${ }^{2}$ Department of Management, Sapienza University of Rome, Rome, Italy \\ ${ }^{3}$ Department of Medicine, Surgery and Dentistry, University of Salerno, Baronissi, Italy \\ ${ }^{4}$ Department of Management and Innovation Systems, University of Salerno, Fisciano, Italy \\ Correspondence: Debora Sarno, Sapienza University of Rome, Department of Management, Via del Castro \\ Laurenziano, 9, 00161 Rome, Italy E-mail: debora.sarno@uniroma1.it
}

Received: November 8, 2018

doi:10.5539/ijbm.v14n2p34
Accepted: December 19, 2018 Online Published: January 25, 2019

URL: https://doi.org/10.5539/ijbm.v14n2p34

\begin{abstract}
Sustainability is a fundamental concern of our times and is particularly important in healthcare, since people are embedded in the healthcare systems on which their health and the viable usage of resources depend. Due to the complexity of healthcare systems, both in terms of governance and pathways from decisions to behaviours, there is no one-size-fits-all theory, but solutions have to be co-created with the actors operating within the systems. This paper proposes case theory as the methodological approach to analyse and interpret cases in order to identify theories suitable for sustainable healthcare systems. Case theory is a recent extension of case study research that includes network theory and systems theory. An example of a case from an Italian regional healthcare system dealing with stroke patients is presented to show how several methods can be mixed and how a substantive theory emerges.
\end{abstract}

Keywords: case theory, service research, case study research, network theory, systems theory

\section{Introduction}

It is widely known that the increasing demand for healthcare services is mainly due to the growth and ageing of the population, the rise of chronic diseases and the increased access that developing countries have to specialized care (OECD, 2017). Notwithstanding the predictability of this scenario, current healthcare systems are still affected by many problems (OECD, 2017), which can be classified according to the economic, social and environmental dimensions of sustainability (Elkington, 1998; U.N.G.A., 2005). Indeed, the unit cost per patient treatment is increasing due, for example, to the development of high technology equipment and drugs. Social issues such as a decrease in the quality of life of patients and their relatives and a lack of healthy education, civil rights, equality, and patient empowerment are pervasive (Hussain et al., 2018). Environmental concerns have only recently been raised related to the cost-ineffective utilization and protection of resources. For example, pollution is not only due to transformation and transportation activities unrelated to healthcare systems but also to the use of technologies and drugs in medicine: available resources are ruined for exogenous and endogenous reasons, thus impacting wellness. Based on the aforementioned reasons, it seems clear that there is a call for integrated responses to these problems oriented towards the overall sustainability of healthcare systems (W.H.O., 2018).

From the managerial point of view, healthcare systems have been recognized as complex adaptive systems (CAS) since they are non-linear, dynamic, and composed of intelligent, independent agents (each part is governed by its own rules (Holland, 1992)) with different goals and behaviours (Rouse, 2008). The absence of a single point of control (no one is "in charge") and the inner intelligence of each part (with the consequent learning and adaptation capabilities) imply that CAS are characterized by self-organization, so they can be more easily influenced than controlled (Begun et al., 2003). Both decision-making systems and pathways from decisions to behaviours are very interesting to analyse (Carrubbo et al., 2017). Indeed, as opposed to traditional systems, the organizational behaviours of CAS depend, among others, on leadership, incentives and inhibitions, outcomes, and personal commitment (Rouse, 2008).

Elaborating on the conceptualization of healthcare systems as CAS, the USA Institute of Medicine (1990) stated 
that "it is more helpful to think like a farmer than an engineer or architect in designing a health care system. Engineers and architects need to design every detail of a system [...] because the responses of the component parts are mechanical and, therefore, predictable. In contrast, the farmer knows that he or she can do only so much... [He] simply creates the conditions under which a good crop is possible" (pp.314-315). This similarity is very peculiar: every healthcare system actor should feel like a farmer inspired by the principle of "creating the best conditions". However, while there are many publications related to the optimization of healthcare systems in terms of maximization of effectiveness and efficiency (Hans et al., 2012; Sarno, 2017), only a few studies have adopted a more comprehensive interpretative framework and approach oriented towards sustainability (Prada, 2012; Fischer, 2015; Saviano et al., 2018); studies based on, or at least applicable to, real systems, are still needed.

These considerations are in line with Henry Mintzberg's myth \#2 of healthcare, which states that healthcare systems can be fixed by clever social engineering driving the change from the top (Mintzberg, 2017). In contrast, it has been recognized that there is no one-size-fits-all solution, and every problem should be treated in its own context. Thus, solutions to better manage healthcare and create the conditions for "optimum crop" should come from the ground level, where there are experienced and engaged with by people dealing with everyday challenges (Mintzberg, 2012). This should be achieved not by "doing things to people" but by "doing things with people" and co-creating with them (Gummesson et al., 2018).

Thus, given the call for sustainability and the complexity of healthcare systems, successful strategies able to create favourable conditions should be grounded on robust theories derived from the interaction with the people who are operating within them. Case theory (Gummesson, 2017) is guided by the complexity paradigm and, for this reason, it puts emphasis on interactive research. It is a recent extension of case study research (Yin, 2014) to include two languages that can face complexity in a more systematic and structured way: network theory and systems theory. Due to its characteristics, case theory is suitable as the service research methodology (Gummesson, 2014), and it contributes to the development of new theories and theory testing (comparisons with extant theories). Thus, the research question (RQ) investigated in this paper is as follows:

RQ: Can case theory support theory generation for sustainable healthcare systems?

The remainder of the paper is structured as follows: in Section 2, a brief literature review on sustainability and sustainable healthcare systems studies is reported; Section 3 addresses the main characteristics and methods of case theory; in Section 4, a straightforward example of case theory applied to a healthcare system struggling for sustainability is shown; implications follow.

\section{Sustainable Healthcare Systems}

Given the concern for the future of healthcare systems, individuals and public/private institutions have started to raise awareness about sustainability issues, even trying to adopt strategies to incorporate some managerial solutions in the existing systems. Indeed, sustainable development addresses harmonizing social-ecological systems (Berkes et al., 2003) and socio-technical systems (Trist, 1981). Sustainability can be seen as both an outcome and a goal, since it entails the building of dynamic capabilities within a system to meet internal and external challenges of the continual regeneration of economic, environmental, and social resources in order to not lose options for the future (Lifvergren et al., 2015). Thus, a sustainable healthcare system is designed to meet the health needs of people, resulting in optimal outcomes that are able to adapt to cultural, social and economic conditions without compromising the possibilities of future generations (Prada, 2012).

Six pillars of healthcare systems sustainability were synthetically recognized in Prada (2012): disease prevention and health promotion; attention to structure, processes, and approaches; affordability of financial resources and investments; innovation; development of human resources; and government policies outside of healthcare. To better highlight the environmental role in sustainable healthcare systems, another study (Fischer, 2015) proposed five pillars:

- disease prevention and health promotion;

- long-term strategic perspective and innovation, reflecting the economic/strategic perspectives among policy makers;

- quality, or the degree to which health care services increase the likelihood of desired outcomes consistently with current professional knowledge (Institute of Medicine US, 2001). Quality is a determinant of sustainability because its lack would imply a decrease in the acceptance of the cost sustained for it;

- institutionalization of environmental concerns (in terms of both social and ecological environments); 
- institutional accountability (to balance the resources invested with the expected long-term stability of the system) and individual responsibility (patient empowerment to decrease their dependence on gatekeepers).

Although general, these conceptual frameworks are probably not exhaustive in covering all sustainability issues. For example, another research has dealt with the role of organizational commitment in healthcare sustainability, highlighting how training, mentoring, leadership, effective management practices, readiness to adapt, willingness to collaborate and other leverages truly influence sustainability strategy implementations in the long run (affective, normative and continuance (Goh \& Marimuthu, 2016)). Thus, the social capital dimension has to be strengthened through cooperation among citizens and professionals in planning and evaluating healthcare services (Botturi et al., 2015) and by focusing on the personalization of care paths (Borgonovi \& Compagni, 2013). Other dimensions of the sustainability of healthcare systems have been identified in the effectiveness of resource allocation. To this extent, a practical tool was developed to evaluate disinvestment feasibility in Australian health services (Harris et al., 2017).

To become theories for sustainable healthcare systems, the different frameworks and pillars identified in these studies should be validated against real data and compared to other theories.

Case study research has been recognized as a qualitative method (Yin, 2014) able to produce the best theory derived from real cases (Walton, 1992). Several publications adopted case study research to derive findings suitable to interpret the role of sustainability in healthcare systems - for example, by dealing with intellectual capital in regional healthcare services by means of semi-structured interviews and focus groups (Cavicchi, 2017). An example of action research (a type of case study research requiring the practical involvement of the researcher in the case (Clark, 1972)) with different waves of interviews was reported for a Swedish hospital coping with sustainability and transformation (Lifvergren et al., 2015). In an attempt to explore methods to identify technologies and practices suitable for disinvestments and drive the implementation and evaluation of relative projects, both case study research (with mixed methods and tools such as interviews, workshops, consultations, etc.) and action research methodologies were adopted (Harris et al., 2017).

To become theories for sustainable healthcare systems, the different findings of these studies should be generalized.

In summary, to conduct an impactful research on sustainable healthcare systems (i) theoretical conceptual frameworks should be validated against real data and operationalized in practical cases (the limit of the former studies) and (ii) empirical findings should be generalized to become theories (the limit of the latter studies). In other words, new theories can emerge from (and are confuted by) the interplay between extant theories and quantitative and qualitative methods adopted to analyse real cases.

Recently, case study research has been elevated to "case theory" by Gummesson (2017). It faces complexity incorporating network and systems theory and emphasizing action research and the role of the researchers in understanding complex issues, possibly resulting in theory generation and testing, as described in the following section.

\section{Facing Complexity with Case Theory}

Cases allow to address complexity by studying "numerous factors and their links and interactions in dynamic context" (Gummesson, 2017, p.8). The scientific contribution of case theory is the conceptualization of cases as the ground for theory generation, reporting, conclusions and practical applications. Thus, the expression "case theory" covers both the process of knowledge generation and the outcome (the new knowledge) of the generation process, constantly performing comparative analyses among new concepts, categories and theories that already exist in a continuous process of validation and generalization of theory.

Case theory answers the need to better ground theory in the real world, making efforts to generalize data towards grand theory and giving back condensed complexity to mid-range theory in the form of facilitated actions (Fig. 1). In particular, it has the following purposes:

- Particularization, in the sense that it can allow to solve specific problems in a specific real context;

- Generalization, because it can be adopted to generalize results from particular cases (Flyvbjerg, 2006) in terms of substantive theory to be adopted in similar cases or towards generalization to mid-range (more general models, frameworks, etc., such as the Boston Consulting Group Model or the model for 5 Forces of Competition) and grand theory (more abstract and general theories, such as Service-Dominant logic). 


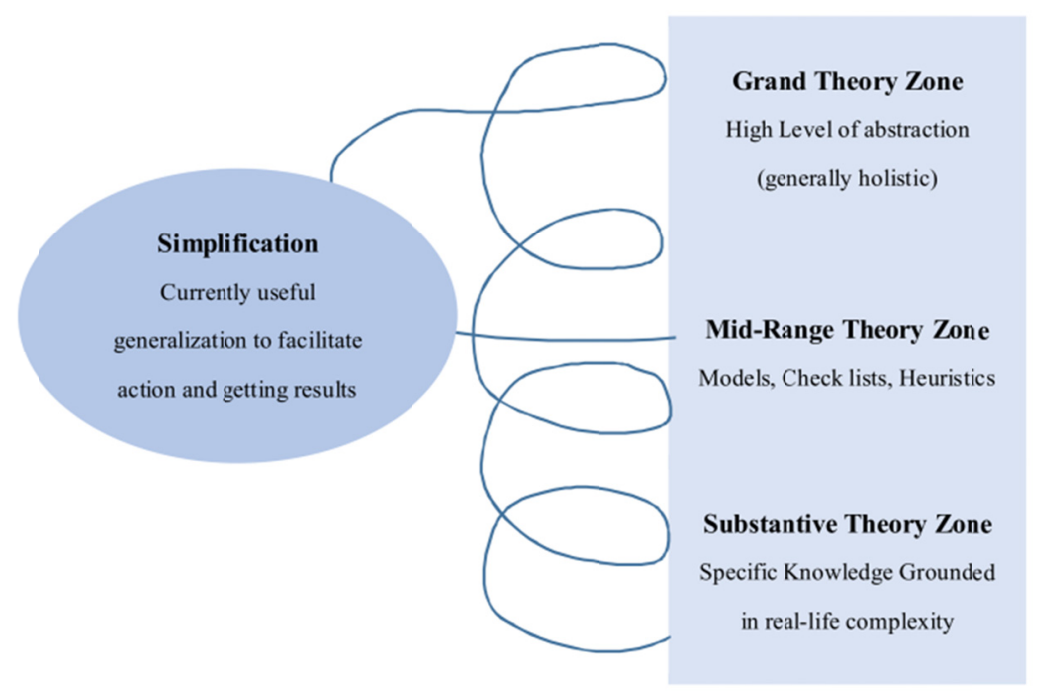

Figure 1. The iterative process of theory generation and testing (Adapted from: Gummesson, 2017)

There are several reasons to appreciate case theory.

First, since social phenomena are complex, some of the attempts to make them linear, such as considering the independences of variables and simple cause-effect relationships while taking statistical surveys for granted, can be irrelevant for new theory generation. In contrast, case theory incorporates theories, such as systems theory, to address complexity and accommodate multiple dimensions of reality.

Second, in the same vein, it must be recognized that reality is ambiguous. Categories should not have fixed boundaries, as crisp sets adopted in quantitative studies, but it should be accepted that, apart from their core meaning, there are gradual overlaps with other adjacent categories (fuzzy sets).

Third, since human properties, behaviour and interactive relationships play a central role in complex phenomena, which is in contrast to a conceptualization of the researcher as being detached from the problem being analysed, case theory puts emphasis on interactive research, asking for a close interaction between the researcher and the object of the study, data, respondents, etc. Moreover, since knowledge can be explicit but also implicit, the involvement of the researcher in the complexity of the problem is fundamental to determining reflections and dialogues and attempting to make the implicit explicit (Nonaka \& Takeuchi, 1995). Such involvement can allow the researcher to better understand complexity and its interactive properties, possibly generating better theory and arriving at the simplicity needed in practical work. However, this also implies that the persona factor and researchscape must be taken into account when analysing and deriving conclusions from case studies.

Fourth, case theory suggests overcoming the traditional categories of quantitative and qualitative research methods since they are just two of many characteristics of a research approach. Every research method is "affected" by subjective, intersubjective, and qualitative judgements and tacit elements. Instead, case theory is a mixed methods approach, encompassing numerous methods and techniques. Moreover, it suggests adapting each application to the context of the research.

Since narratives typical of case study research are fundamental in the conceptualization of the cases but are limited, Gummesson (2017) extended traditional case study research (see, among others, Yin, 2014), grounded theory (Glasser \& Strauss, 1967), and hermeneutics and interpretative research (Ödman, 1985) to include languages that deal with complexity in a more structured and systematic way-network theory and systems theory - as well as fuzzy sets, chaos theory and eventual computer simulation. These theories and related methods are added to the dominant qualitative and verbal language of traditional case study theory.

Given the nature of this methodological approach, research plans are dynamic and tentative, and there are multiple data generation methods (from interviews, to observation, to neuroscience, etc.); every analysis should be followed by an interpretation.

Network and systems theories are summarized below, along with the current research paradigm of service research, which should inspire sustainable healthcare systems but also be propelled by case theory (Gummesson, 
2014).

\subsection{Thinking in Service, a Value Co-Creation Perspective}

The adoption of case theory should take advantage of the service perspective, which can be very successful for analysing healthcare systems targeting sustainability because it shifts the focus from the goods to the service that actors exchange within these systems.

In a healthcare setting, the focus on goods ("Good-Dominant logic") manifests in the spread of more specialized drugs, equipment, facilities and procedures. According to the Good-Dominant logic, some actors (parties) are in charge of producing and delivering goods, while others are in charge of consuming them, passively receiving the value the formers provide. This is revealed in the fact that the ill-person is called "patient", referring also to the fact that he/she needs to wait without asking or getting irritated for healthcare services (Gummesson, 2001). Thus, Good-Dominant logic seems to be the logic of division between actors. It addresses nouns, such as laboratory tests, nurses, and medications, and it does not take into account that patients do not need goods but rather solutions to their health problems and wellness.

In contrast, the min-set of Service-Dominant logic has been developed (Vargo \& Lusch, 2008; 2016). This logic is the logic of togetherness and verbs, such as caring, monitoring, and visiting (Joiner \& Lusch, 2016). Service-Dominant logic is based on the assumption that no value can be obtained in isolation, but value is derived from exchanges, interactions, and collaborations. Value is co-created by all involved parties that integrate different types of resources (private, such as friends and families, or public, such as nature, laws, or protocols), knowledge and goods. Thus, the value co-creation process takes place when actors integrate their resources and exchange service, which is the application of competences and other resources for the benefit of another party. In summary, goods are only service distribution mechanisms. Moreover, value is subjectively perceived by each party depending on his/her information variety, needs, and the context of value co-creation (Polese et al., 2016; Polese, 2018). Therefore, even taking an appointment for a visit can be valuable - or not-for the parties involved (Kim, 2018) depending on the agreement on the date/time based on these characteristics (for example, the resources available to the patient to travel to the appointment or the availability of the equipment for the physician).

Adopting a service perspective, Gummesson et al. (2018) stated that the Italian healthcare system needs new strategies that are not just planned but also emergent, new organizations designed to encourage distributed leadership, new managerial stiles oriented to meet patients' expectations, and new, humanized measurement scales.

Reynoso (2009) connected value co-creation to sustainability, stating that a balanced integration of economic, social and environmental aspects is the foundation of value co-creation. Accordingly, Saviano et al. (2017) explored the interests of service research in the topic of sustainability, finding a low but increasing rate of usage of the word "sustainab*". Then, based on the sustainability literature, they listed some key requirements for global engagement in the challenge of sustainability in light of the service research: multi-stakeholder engagement and participatory process (addressable by means of concepts such as value co-creation and consonance of the Viable Systems Approach (Golinelli, 2010)), cultural change through education (T-Shaped professionals to improve not just the technical but also the comprehension capabilities of managers), and a multi-perspective approach with interdisciplinary thinking and systems thinking (such as the developed Viable Systems Approach and Service Science (Maglio et al., 2009)).

\subsection{Thinking in Networks, a Relational Perspective}

Case theory suggests adopting network theory, which can be very successful in analysing healthcare systems that are targeting sustainability, because it allows for the identification of the actors involved and their relationships. Thus, it provides the researcher the whole picture of the value co-creation networks (Enquist et al., 2015).

According to the relational perspective, reality is seen as a set of relations (links) linking actors (nodes), which allows to describe - with various degrees of sophistication - the existent possible interactions among the components of a network, translating the narrative description of a case into advanced graphs and mathematics. When enlarging the analysis from one dyad of actors to the whole context, many-to-many marketing is investigated (Gummesson, 2004). Many-to-many marketing, initially inspired by the IMP researchers (Wilkinson, 2008), "describes, analyses and utilizes the network properties of marketing" (Gummesson, 2008).

The general definition of networks attributes to them a scale-free meaning (that is, there is no limit to their size) and a random occurrence. In marketing and management (Gummesson \& Polese, 2009), networks are built and defined for a purpose, which requires control and gives rise to limited and planned networks. Partners, suppliers, 
shareholders, and other stakeholders offer access to external resources as an alternative to a company acquiring its own resources. A member of a network based on cooperation cannot solely maximize its own benefits at all times but - within reasonable limits - has to show respect for the other members. Moreover, there is a cost for building, maintaining or finding a network.

There are several concepts and properties of networks (Barabási, 2002) that can be very useful for analysing a real case, looking for peculiarities, commonalities, etc., thus enlarging the power of narratives. For example, by drawing a network, it is possible to identify clusters (dense grouping of links and nodes in which every actor can easily reach the others), while a cluster coefficient is a measure of the closeness of belonging actors. A hub, in contrast, is an actor (individual or organization) with a particular attraction to others (measurable in terms of fitness). A centralized network presents one hub.

Several studies have adopted network theory in healthcare systems, as Gummesson (2017) did by comparing the Canadian Shouldice Hospital to a Swedish hospital to understand the unique value proposition of the former.

\subsection{Thinking in Systems and Eco-Systems, Holistic and Institutional Perspectives}

Case theory suggests adopting systems theory (Bruni et al., 2018), which can be very successful in analysing healthcare systems that are targeting sustainability from a holistic perspective. Moreover, the eco-systemic view of Service-Dominant logic (Vargo \& Lusch, 2016) allows for addressing the role of institutions (rules, norms, symbols, etc.) in orienting interactions among actors in healthcare systems.

Systems thinking shifts the focus from the parts (reductionism) to the whole (holism, where the whole is not just the sum of its parts (Checkland, 1997)). Thus, in healthcare settings, the focus is shifted from drugs, facilities, equipment, etc. (the "components") to how the components are organized and behave (the "whole"). Moreover, a holistic perspective takes into account the relationships among the parts and the whole. Thus, the universality of health can be interpreted as a sound principle because healthy people handle their lives better and are able to contribute to the nation in which they live and its health (Gummesson et al., 2018).

Based on systems thinking, the Viable Systems Approach (Golinelli, 2010) assumes that every system is oriented towards a purpose and is viable (it wants to survive over time) (Barile \& Saviano, 2011). A system should be aligned to supra-systems, which are other systems that retain critical resources for the original system's survival (Barile \& Polese, 2010). To be aligned, a system shows adaptation traits both as autopoiesis (self-organization (Maturana \& Varela, 1975)) and homeostasis (auto-regulation (Beer, 1975)). Alignment among systems can be measured in terms of consonance (similarity of information varieties, Barile et al., 2013) and resonance (positive harmonic interaction to achieve a common goal). The Viable Systems Approach community has developed a thorough understanding of sustainability. Among other topics, the community has analysed the intersections among the three spheres of sustainability and the dynamics of the resulting helix (Scalia et al., 2018). Moreover, the relationships among efficiency, effectiveness and sustainability have been defined and state that efficiency is a primary short-term goal of every system's process, effectiveness is a target based on an extended perspective of the organization and its strategies, and sustainability is a wider measure of the overall activity of the system operating in its environment (Barile et al., 2014). A recent study based on the contribution of Viable Systems Approach to sustainability in healthcare systems was developed by Saviano et al. (2018).

According to service science, an initiative developed by IBM with a clear technological focus, service systems (Maglio \& Spohrer, 2018) are configurations of people, technologies, and other resources that interact with other service systems to create mutual value.

Among quantitative methods to address complex systems, system dynamics (Stermann, 2000) is a modelling and computer simulation technique that describes the behaviour of systems when variables interact.

In Service-Dominant logic, the metaphor of natural (eco)systems has been adopted to analyse networks of actors who need resources to survive under a service ecosystem view (Akaka et al., 2015). In service ecosystems, actors gain mutual benefit from co-creating value together while their actions are enabled and constrained by shared rules, norms, practices, interpretation schemes and beliefs, which are together named institutional arrangements (Vargo \& Lusch, 2016). According to Service-Dominant logic, actors choose to engage in resource integration with other actors by interpreting, in light of the institutional arrangements (potential resourceness (Koskela-Huotari \&Vargo, 2016)), their value co-creation potential. Finally, service ecosystems are self-adjusting because social practices are responsive to the changes according to the agency of the individuals acting within (Peters et al., 2010). Several studies have analysed the behaviours of healthcare systems under a service ecosystem view (Frow et al., 2016; Gambarov et al., 2017) 


\section{Adopting Case Theory for a Sustainable Healthcare System: An Example}

The presentation of the following short case has the objective of intuitively showing how many insights can be easily derived by adopting a case theory methodological approach, both in terms of theory building (by using case theory to solve problems) and theories comparison and generalization (to compare different theories or simplify findings to make them more theoretical and abstract). Thus, the case-presented in the form of a narrative - exemplifies some of the concepts expressed in the paper. However, in practical implementations of case theory, rigorous descriptions of research the method, context, analysis and findings must be reported.

The case dealt with an Italian healthcare system for stroke patients struggling for sustainability (stroke and other circulatory diseases are responsible for more than one in three deaths in the world, OECD, 2017). The case initially focused on 1 medical unit (12 beds) of a regional university hospital with its nurses and physicians; then, it was enlarged to a regional technical committee of more than 20 participants from different institutions. Finally, it was widened to a national level, as reported below.

The purpose of studying this case was to extend the understanding of sustainability in healthcare systems while helping involved actors make decisions to increase the sustainability of their systems. In particular, the research questions were as follows: how can traces of sustainability in this healthcare system be identified, or how can the sustainability be increased, possibly in terms of innovative social, economic and environmental practices? How can some new theories eventually be derived from that? How can it be ensured that these traces are "better" than other traces identified in other systems? How can sustainability principles be incorporated into the education, values, skills and common practices of the actors of this system?

The access to case data was simplified since, as researchers, professors in healthcare management, co-founders of medical devices start-ups, friends of patients, and friends of physicians, the authors were actively involved several times in the healthcare system for more than 5 years. The authors were actually actors in this healthcare system.

As researchers, they were asked to identify a method for sizing the nursing staff in a hospital (Sarno \& Nenni, 2016). As marketing and management professors, they had to explain to students what the production implications of a clinical pathway are (capacity or resources, etc.) and how the national healthcare systems manage reimbursement to healthcare providers using the stroke case as an example. As entrepreneurs, they interacted with RX-machine providers to test the effectiveness of new dosimeters to measure radiations during diagnostic exams. As friends of patients and physicians, they paid attention to the symptoms of their relatives, took them to hospitals and rehabilitation structures, participated in medical workshops, talked about electronic health records, and collected paper medical records. In summary, with different roles, needs, purposes, resources, knowledge, and institutions, they interacted many times with multiple actors, building a basic understanding and explicit knowledge related to the case study of the management of such a healthcare system under the pressure for sustainability considerations.

The number of actors, purposes, resources, relationships, and institutions involved was clearly huge, and the system appeared to be a Complex Adaptive system with decentralized power control. This scenario was fitting for case theory.

Different theories were mixed under a service perspective. At first glance, according to network theory, it was clear that the network of actors (including the hospital actors, the post-discharge facilities, the drug and equipment providers, the universities - for education and research purposes- the citizens, etc.) was fragmented. Some nodes were more connected than others as attractors for the remainder of the network. In particular, a group of physicians from the hospitals, some professors from the university, and a group of doctors from the rehabilitation network participated in a technical voluntary committee promoted by the region to try to integrate their practices, aligning the education of students from medicine to the best practices developed in the hospitals, and, at the same time, trying to adopt homogeneous treatments in hospitals and in the post-stroke network. A set of nodes partially overlapping with the previous nodes decided to fund a committee to compare their strategies, tactics and operations with those of other hospitals in other Italian regions to identify the most effective way to manage stroke patients and obtain the highest outcomes. This committee included some of the authors.

By analysing the work of the committee as a case within a case, it is possible to identify a wide mix of methods adopted to derive practical solutions (Fig. 2). Following the basics of case theory, they started drawing their own networks and developing a graphical representation (as a flowchart) of the adopted clinical pathways to make comparisons. Some parameters - as key performance indicators of clinical and managerial activities (such as the average length of stay collected for each stroke patient category) and as results of stakeholders' satisfaction surveys, both weighted on the case mix treated by the different stroke units-were chosen to make the 
comparisons more accurate. Incidentally, the survey was based on the findings of a system dynamics model (Stermann, 2000).

Finally, while the initial objective of the research was the outcome effectiveness in the context of the regional healthcare system, the committee recognized that there was a tacit objective to take efficiency into account and answer the call for environmental concerns of national and international organizations. These tacit goals were later translated into explicit ones named the social, economic and environmental areas of sustainability of the stroke healthcare regional system even if they were based on fuzzy sets (for example, the change of demission rate in 6 months after the development of a new regional guideline- used to measure the flexibility of the hospital - addressed both economic and social dimensions of sustainability). In particular, the sustainability strategy of the committee was defined according to the five pillars proposed by Fischer (2015) in terms of prevention and the promotion of health in the geographical area, the long-term perspective on innovation in drugs and treatments, the quality of care (even in terms of possible hospitalization at home (Polese et al., 2018)), environmental concern, and patient empowerment and responsibility. Moreover, a focus on organizational commitment was introduced. The initial set of key indicators was extended and clustered for each pillar, and a target was set out for each pillar to identify the structures that were able to perform better. The different practices were analysed and compared in terms of processes, equipment and other resources, and actors involved to identify the best practices. To this extent, a system dynamics model and the analysis of supra and sub-systems of Viable Systems Approach were adopted. Indeed, causal relationships among the variables determining the values of the parameters were shown based on the understanding of the influences of the different actors participating in or impacting the system. Then, several what-if analyses were performed to finally develop common guidelines to implement sustainability practices. For example, to speed the decision process related to the particular lifesaving treatment of thrombolysis, guidelines were provided to educate the first aid personnel (on the ambulance) to quickly recognize stroke symptoms, evaluate the possibility of administrating a specific class of drugs, and inform the hospital before arrival at the emergency department of the need for treatment.

From a service ecosystem perspective, the "sustainability inspired" guidelines are institutions co-created and shared by actors who are willing to cooperate. In such an ecosystem, value co-creation processes are simplified, since actors already know and agree with the same "rules of the game" and are facilitated to integrate resources and exchange service since they better perceive and understand the value propositions of the other actors. As an example, after the release of the report of the committee, other actors agreed to change processes to align to the guidelines and temporary exchange personnel. Thus, these common guidelines, as boundary objects (Sajtos et al., 2018), became the facilitators to aggregate new actors into the network (enlarging the ecosystem) and favour more cohesion within it.

Moreover, due to the growth of the network and the importance of the initiatives supported by it, the development of a new information system for patient medical records was financed by the regional healthcare department. The design of this software was inspired by service systems principles. The software was oriented not just to keep medical records but also to allow the different actors (medical records stakeholders) to co-create value on a common platform: tele-medicine initiatives were carried out, and patients were allowed to take part in decision making processes by expressing preferences on visits and self-annotating their health statuses. The software was used as an engagement platform (Storbacka et al., 2016) to communicate healthier lifestyles and the availability of new healthcare services. Furthermore, while respecting privacy laws, social networking was facilitated by specific software functions to allow patients with similar problems to connect and share experiences, making patients and their relatives more empowered.

Analysing the software introduction through the lens of case theory, it can be found that, after its first release, value co-creation in the network increased actors' engagement, and engagement increased participation in the service ecosystem in a positive reinforcing loop (a higher number of active participants on the committee and in the healthcare system was recorded).

These are some of the reasons that explain why, when the study of the committee was repeated two years later to further enlarge the network, it was found that the sustainability targets set at the initial stage were achieved and overcome. 

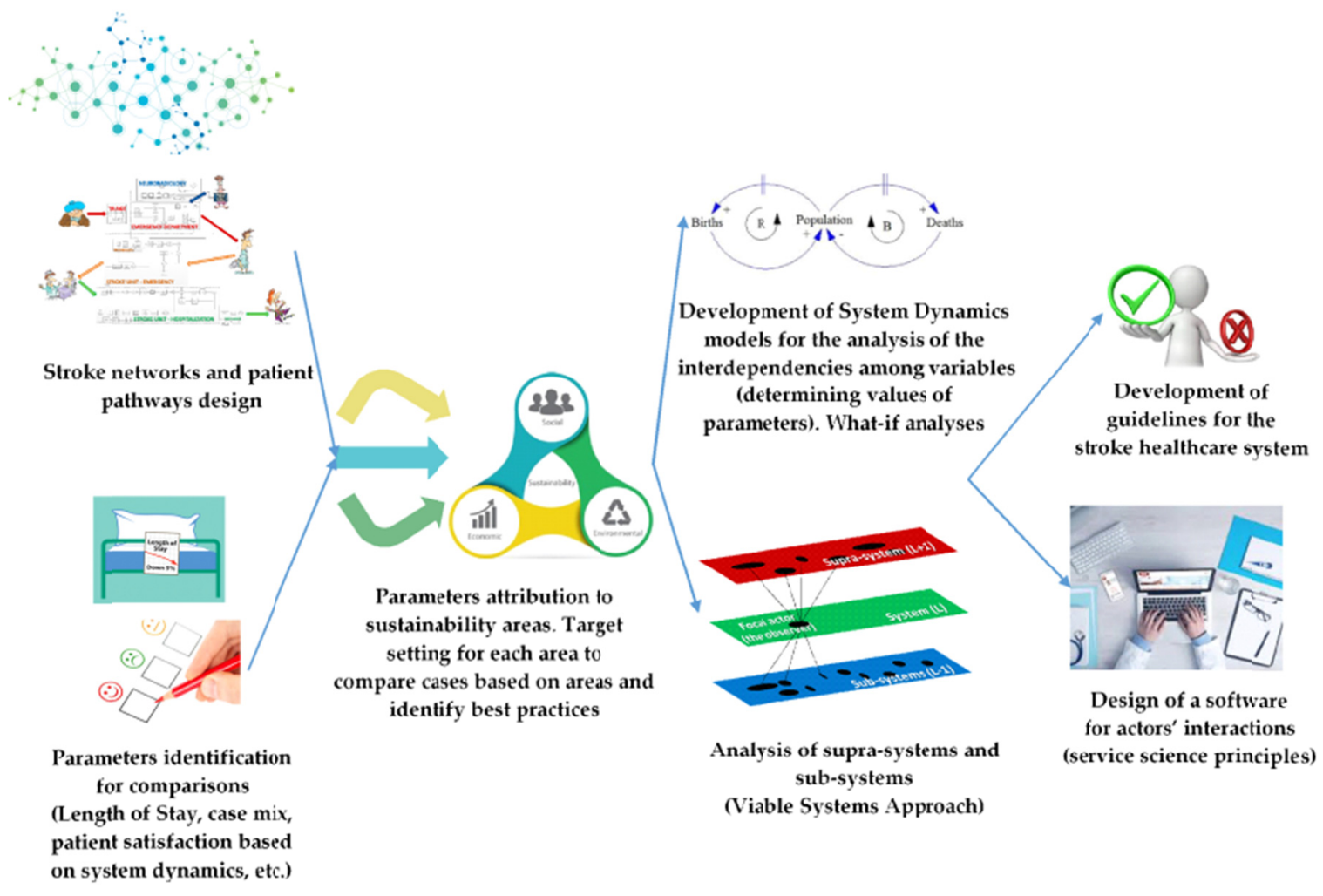

Figure 2. Mix and sequence of methods adopted in the case

In an attempt to analyse and interpret the data from this case, it can be stated that some of the characteristics of the clinical, managerial and educational processes adopted in the service ecosystem were due to the local government, local facilities, regional regulations, skills and knowledge of the professionals involved and available workforce. Thus, specific features of the context may have influenced (positively and negatively) the emergence of small, pro-active groups and the engagement of their participants in the undertaking of sustainability initiatives. Thus, further studies based on, for example, the Viable Systems Approach, may be focused on the determinants of structural conditions (consonance among actors) for the subsequent behaviours of actors (resonance) that are oriented towards sustainability.

Moreover, as time passed, the institutions were revised (and improved) to incorporate more actors participating in the patient clinical pathway (for example, inside the hospital, adding cardiologists, diabetologists and speech therapists to the initial set of professionals involved in clinical pathway design, such as radiologists, neurologists, physiotherapists, and nurses). It can be deduced that local rules, strategies and performance indicators informally became a substantive theory for the closest stroke service ecosystems - eventually starting to overlap with them in other regions - or for other medical issues (being generalized as a mid-range theory).

This short case describes the adoption of case theory, both as theory generation and as theory testing, highlighting the usefulness of case theory in contributing to the management and understanding of sustainable healthcare systems. In the example, it is evident that case theory does not oppose other quantitative and qualitative methods. Instead, it provides a wider conceptual ground on which to develop further studies, as it is a mixed methods approach by nature. However, further and deeper analyses of this and other cases that take into account the characteristics of the operating contexts are needed to practically contribute to sustainability theory of healthcare systems.

\section{Implications}

Sustainability is a fundamental concern of our times and is particularly important in healthcare, since people are embedded in the healthcare systems on which their health and the viable usage of availlable resources depend. Since healthcare systems are complex adaptive systems, there is the need to identify ways to create conditions for sustainable strategies, tactics and operations of every type of healthcare system actor. Moreover, since the 
behaviour of these systems is context-dependent, there is no one-size-fits-all theory, but solutions must be co-created with the actors operating within the systems. This paper proposes case theory as the methodological approach to analyse, interpret and identify theories that are suitable for sustainable healthcare systems. Indeed, this paper adopts interactive case study research (asking about the service-oriented involvement of researchers in the systems and co-creating value with the other actors), and it introduces a system and network approach to face the complexity of real cases. A straightforward example from the real case of an Italian regional healthcare system dealing with stroke patients is presented to show how several methods can be mixed in the research plan and how a substantive theory emerges and is institutionalized due to the continuous cycle of comparison with other theories and improvement of the current one, thus enlarging the number and variety of the cases examined. Several theoretical and practical implications are derived from this.

First, the literature review reveals that there is still a lack of a clear understanding of the sustainability variables in healthcare systems, which makes it difficult to even state that current theories have been error-proofed. To the contrary, sustainability issues should be addressed based on appropriate methods to address complexity, accepting that no theory will survive forever, also because they are context-dependent.

Second, based on case theory and its adoption in the presented case, sustainable healthcare systems need guidelines developed by the "community". Indeed, from a system point of view, since healthcare systems are CAS, there is no single point of control, and self-organization is required. However, resources are scarce, particularly in universalistic systems, and sustainable self-organization can be achieved only with difficulty. Here, the focus on a few simple rules creates the conditions for the emergence of viable systems - as opposed to complicated procedures and processes that can be developed by technicians but may not be applicable to real systems (myth \#2 of Mintzberg). Moreover, from a service ecosystem perspective, guidelines developed by groups of involved actors are already aligned to the other shared institutions of the ecosystem, not only in terms of laws and rules but also in terms of symbols, current practices, and beliefs. This also implies that the other actors can easily engage in resource integration and service exchange according to the new guidelines. The information variety alignment of actors can be evaluated by means of measures of consonance and resonance of the Viable Systems Approach. Finally, from a network perspective, it becomes clear that it is useful to organize around existing connections, increasing attractiveness by co-creating new meanings to relationships rather than focusing on vertical silos of knowledge, which encourage only the local optimization of processes and lose the view of the whole picture.

Third, the importance of the role of T-shaped professionals is confirmed (Saviano et al., 2018), since these professionals not only understand sustainability principles but also possess the capabilities needed to be the driver of change by cooperating, negotiating, and leading the other actors towards sustainability decisions and goals.

Fourth, as "practical theories" that are adaptable to contexts and re-comprised in case theory, systems and network theories are confirmed to play a fundamental role in healthcare systems (Polese, 2013; Polese \& Carrubbo, 2016; Gervasio et al., 2017; Sarno, 2017), while case theory further helps to systematize their findings.

Fifth, the interplay between cases and theories; abduction, induction, deduction; particularization and generalization of results are endless. According to case theory, healthcare sustainability studies that are already published may be combined and tested in real cases, taking case theory as a wider framework. With a top-down approach, case theory may help to compare current mid-range sustainability theories and look for the best theory to try to introduce to healthcare systems. Moreover, abstraction from healthcare systems theories may be helpful in deriving a grand theory of sustainability. Finally, new, detailed case studies based on case theory are welcome. Thus, the journey in "methodologyland" opened by case theory does not end in this paper.

\section{References}

Akaka, M. A., Vargo, S. L., \& Lusch, R. F. (2015). An exploration of networks in value cocreation: a service-ecosystems view. Special Issue - Towards a better understanding of the role of value in markets and marketing, 9, 15-50. https://doi.org/10.1108/S1548-6435(2012)0000009006

Barabási, A. L. (2002). Linked: the new science of networks; Perseus: Cambridge, Ma.

Barile, S., \& Polese, F. (2010). Smart service systems and viable service systems: Applying systems theory to service science. Service Science, 2(1-2), 21-40. https://doi.org/10.1287/serv.2.1_2.21 
Barile, S., \& Saviano, M. (2011). Foundations of systems thinking: the structure-system paradigm. Barile, S. (Ed), Contributions to theoretical and practical advances in management, A Viable Systems Approach (vSa); Aracne, Roma: IT, 1-25.

Barile, S., Polese, F., Calabrese, M., Carrubbo, L., \& Iandolo, F. (2013). A theoretical framework for measuring value creation based on the Viable Systems Approach (vSa). Barile, S. (Ed), Contributions to theoretical and practical advances in management, A Viable Systems Approach (vSa); Aracne, Roma: IT.

Barile, S., Saviano, M., Iandolo, F., \& Calabrese, M. (2014). The Viable Systems Approach and its Contribution to the Analysis of Sustainable Business Behaviors. Systems Research and Behavioral Science Syst. Res, 31, 683-695. https://doi.org/10.1002/sres.2318

Beer, S. (1975). On heaping our science together. Trappl, R., Hanika, F. \& Tomlinson, R. (Eds), Progress in Cybernetics and Systems Research; Vol. II, John Wiley: New York, NY, 3-11.

Begun, J. W., Zimmerman, B., \& Dooley, K. (2003). Health care organizations as complex adaptive systems. Mick, S. M. \& Wyttenbach, M. (Eds), Advances in Health Care Organization Theory, 253-288. Jossey-Bass: San Francisco, CA.

Berkes, F., Colding, J., \& Folke, C. (2003). Navigating Social-Ecological Systems: Building Resilience for Complexity and Change, Cambridge University Press: Cambridge.

Borgonovi, E., \& Compagni, A. (2013). Sustaining universal health coverage: the interaction of social, political, and economic sustainability. Value in Health, 16(1), S34-S38.

Botturi, D., Curcio Rubertini, B., Desmarteau, R. H., \& Lavalle, T. (2015). Investing in social capital in Emilia-Romagna region of Italy as a strategy for making public health work. Johnson, C. D. (Ed) Social Capital: Global Perspectives, Management Strategies and Effectiveness. Nova Science Publishers, Inc., Hauppauge: NY, 197-219.

Bruni, R., Carrubbo, L., Cavacece, Y., \& Sarno, D. (2018). An overview of the contribution of systems thinking within management and marketing. Barile, S., Pellicano, M. \& Polese, F. (Eds.), Social Dynamics in a Systems Perspective, New Economic Windows; Springer, Cham, 241-259.

Carrubbo, L., Iandolo, F., Pitardi, V., \& Calabrese, M. (2017). The viable decision maker for CAS survival: how to change and adapt through fitting process. Journal of Service Theory and Practice. 27(5), 1006-1023. https://doi.org/10.1108/JSTP-09-2015-0202

Cavicchi, C. (2017). Healthcare sustainability and the role of intellectual capital: Evidence from an Italian Regional Health Service. Journal of Intellectual Capital, 18(3), 544-563.

Checkland, P. (1997). Systems Thinking, Systems Practice. Wiley: Chichester.

Clark, P. (1972). Action Research and Organizational Change. Harper \& Row: London.

Elkington, J. (1998). Partnership from Cannibals with forks: the triple bottom line of 21 st-century business. Environmental Quality Management, 8(1), 37-51. http://dx.doi.org/10.1002/tqem.3310080106

Enquist, B., Petros Sebhatu, S., \& Johnson, M. (2015). Transcendence for business logics in value networks for sustainable service business. Journal of Service Theory and Practice, 25(2), 181-197. https://doi.org/10.1108/JSTP-09-2013-0189

Fischer, M. (2015). Fit for the Future? A New Approach in the Debate about What Makes Healthcare Systems Really Sustainable. Sustainability, 7, 294-312. https://doi.org/10.3390/su7010294

Flyvbjerg, B. (2006). Five Misunderstandings About Case-Study Research. Qualitative Inquiry, 12(2), 219-245. https://doi.org/10.1177/1077800405284363

Frow, P., McColl-Kennedy, J. R., \& Payne, A. (2016). Co-creation practices: Their role in shaping a health care ecosystem. Industrial Marketing Management, 56, 24-39. https://doi.org/10.1016/j.indmarman.2016.03.007

Gambarov, V., Sarno, D., Hysa, X., Calabrese, M. \& Bilotta, A. (2017). The role of loyalty programs in healthcare service ecosystems. The TQM Journal, 29(6), 899-919. https://doi.org/10.1108/TQM-02-2017-0019

Gervasio, D., Amaduzzi, A. \& Montani, D. (2017). Methods and Tools to Reorganise the Governance in the Italian Healthcare Companies. International Journal of Business and Management, 12(2), 56-66. https://doi.org/10.5539/ijbm.v12n2p56

Glasser, B. G., \& Strauss, A. L. (1967). The discovery of Grounded Theory. Aldine: Chicago, IL. 
Goh, G. Y., \& Marimuthu, M. (2016). The Path towards Healthcare Sustainability: The Role of Organisational Commitment. Procedia - Social and Behavioral Sciences, 224, 587-592.

Golinelli, G. M. (2010). Viable Systems Approach (VSA). Governing Business Dynamics. Cedam: Padua, Italy.

Gummesson, E., \& Polese, F. (2009). B2B is not an island! Journal of Business \& Industrial Marketing, 24(5/6), 337-350. https://doi.org/10.1108/08858620910966228

Gummesson, E. (2001). Are you looking forward to your surgery? Managing Service Quality: An International Journal, 11(1), 7-9. https://doi.org/10.1108/09604520110366142

Gummesson, E. (2004). Many-to-many Marketing. Liber: Malmö, Sweden.

Gummesson, E. (2008). Extending the new dominant logic: from customer centricity to balanced centricity. The Journal of the Academy of Marketing Science, 36(1), 15-17. https://doi.org/10.1007/s11747-007-0065-x

Gummesson, E. (2014). Service research methodology: from case study research to case theory. Revista Ibero-Americana de Estratégia, 451-463.

Gummesson, E. (2017). Case theory in business and management. 55 City Road, London: SAGE Publications Ltd.

Gummesson, E., Doyle, G., Storlazzi, A., Annarumma, C., Favretto, G., Tommasetti, A. \& Vesci, M. (2018). Health Myths and Service-Dominant Logic. Adinolfi P. \& Borgonovi E. (Eds.), The Myths of Health Care; Springer, Cham, 231-251. https://doi.org/10.1007/978-3-319-53600-2_12

Hans, E. W., Houdenhoven, M., \& Hulshof, P. J. H. (2012). A Framework for Healthcare Planning and Control. In Randolph, H. (Ed.), Handbook of Healthcare System Scheduling. International Series in Operations Research \& Management Science. https://doi.org/10.1007/978-1-4614-1734-7_12

Harris, C., Allen, K., Brooke, V., Dyer, T., Waller, C., King, R., Ramsey, W., \& Mortimer, D. (2017). Sustainability in Health care by Allocating Resources Effectively (SHARE): investigating methods to identify, prioritise, implement and evaluate disinvestment projects in a local healthcare setting. BMC Health Services Research, 17, 1-370. https://doi.org/10.1186/s12913-017-2269-1

Holland, J. H. (1992). Complex Adaptive Systems. Daedalus, A New Era in Computation. The MIT Press, 121(1), 17-30.

Hussain, M., Ajmal, M. M., Gunasekaran, A., \& Khan, M. (2018). Exploration of social sustainability in healthcare supply chain. Journal of Cleaner Production, 203, 977-989. https://doi.org/10.1016/j.jclepro.2018.08.157

Institute of Medicine (1990). Medicare: A Strategy for Quality Assurance. National Academy Press: Washington, DC, USA. https://doi.org/10.17226/1548.

Institute of Medicine (US) Committee on Quality of Health Care in America (2001). Redesigning Health Care with Insights from the Science of Complex Adaptive Systems. Crossing the Quality Chasm: A New Health System for the 21st Century. Washington (DC): National Academies Press (US), pp. 309-317. https://doi.org/10.17226/10027

Joiner, K., \& Lusch, R. F. (2016). Evolving to a new service-dominant logic for health care. Innovation and Entrepreneurship in Health, 3, 25-33. https://doi.org/10.2147/IEH.S93473

Kim, J. (2018). The Effect of Patient Participation through Physician's Resources on Experience and Wellbeing. Sustainability, 10(6), 2102, 1-14. https://doi.org/10.3390/su10062102

Koskela-Huotari, K., \& Vargo, S. L. (2016). Institutions as resource context. Journal of Service Theory and Practice, 26(2), 163-178. https://doi.org/10.1108/JSTP-09-2014-0190

Lifvergren, S., Docherty, P. \& Shani, A. B. R. (2015), Towards a Sustainable Healthcare System: Transformation through Participation. Organizing for Sustainability, 99-125.

Maglio, P. P., \& Spohrer, J. (2018). Fundamentals of service science. Journal of the Academy of Marketing Science, 36(1), 18-20. https://doi.org/10.1007/s11747-007-0058-9

Maglio, P. P., Vargo, S. L., Caswell, N., \& Spohrer, J. (2009). The service system is the basic abstraction of service science. Information Systems and e-business Management, 7, 395-406. https://doi.org/10.1007/s10257-008-0105-1

Maturana, H. R., \& Varela, F. (1975). Autopoietic systems. Report BCL, 0(4), 37-48.

Mintzberg, H. (2012). Managing the Myths of Health Care. World Hosp Heath Serv, 48(3), 4-7. 
Mintzberg, H. (2017). Managing the Myths of Health Care: Bridging the Separations Between Care, Cure, Control, and Community. Berrett-Koehler Publishers, 1-272.

Nonaka, I., \& Takeuchi, H. (1995). The knowledge creating company. Oxford University Press: New York.

Ödman, P. J. (1985). Hermeneutics in research practice. Husén, T. \& Neville, T. P. (Eds), The international encyclopedia of education; Pergamon: Oxford.

OECD (2017). Health at a Glance: OECD indicators. OECD Publishing, Paris. Available online: http://dx.doi.org/10.1787/health_glance-2017-en

Peters, L. D., Pressey, A. D., \& Johnston, W. J. (2010). Sociology, structuration and understanding business networks. Proceedings of 26th Annual IMP Conference (Budapest).

Polese, F., \& Carrubbo L. (2016). Eco-sistemi di Servizio in Sanità, Collana Studi e Ricerche Aziendali, Giappichelli: Torino, IT, 65.

Polese, F. (2018). Successful Value Co-creation Exchanges: A VSA contribution. Barile, S., Pellicano, M. \& Polese, F. (Eds), Social Dynamics in a Systems Perspective, New Economic Windows; Springer, Cham, 19-37.

Polese, F., (2013). Management sanitario in ottica sistemico vitale. Collana del Dipartimento di Studi e Ricerche Aziendali dell’Università degli Studi di Salerno, Giappichelli: Torino, IT.

Polese, F., Caputo, F., Carrubbo, L., \& Sarno, D. (2016). The value (co)creation as peak of social pyramid. Proceedings of the 26th Annual RESER Conference, "What's Ahead in Service Research: New Perspectives for Business and Society”, Naples, Italy, 1232-1248.

Polese, F., Carrubbo, L., Caputo, F., \& Sarno, D. (2018). Managing Healthcare Service Ecosystems: Abstracting a Sustainability-Based View from Hospitalization at Home (HaH) Practices. Sustainability, 10(11):3951. https://doi.org/10.3390/su10113951

Prada, G. (2012). Sustainability: What Does This Mean for Canada's Health Care Systems. Proceedings of the Collaborative Meeting of the Conference Board of Canada's Health-Related Executive Networks. Toronto, ON, Canada, 16 April.

Reynoso, J. (2009). Values - based service for sustainable business - lessons from IKEA. Journal of Service Management, 20(4), 473-475. https://doi.org/10.1108/09564230910978548

Rouse, W. B. (2008). Health care as a complex adaptive system: Implications for design and management. The Bridge. Linking engineering and society, National Academy of Engineering, 38(1), 17-25.

Sajtos, L., Kleinaltenkamp, M., \& Harrison, J. (2018). Boundary objects for institutional work across service ecosystems. Journal of Service Management, 29(4), 615-640. https://doi.org/10.1108/JOSM-01-2017-0011

Sarno, D., \& Nenni, M. E. (2016). Daily nurse requirements planning based on simulation of patient flows. Flexible Services and Manufacturing Journal, 28(3), 526-549. https://doi.org/10.1007/s10696-015-9231-5

Sarno, D. (2017). Organizzazione e Operations Management nei sistemi ospedalieri, Studi MOA. Collana di Management e Organizzazione Aziendale, Editrice Minerva Bancaria, 2, 1-190.

Saviano, M., Barile, S., Spohrer, J., \& Caputo, F. (2017). A service research contribution to the global challenge of sustainability. J. Serv. Theory Pr., 27, 951-976. https://doi.org/10.1108/JSTP-10-2015-0228

Saviano, M., Bassano, C., Piciocchi, P., Di Nauta, P., \& Lettieri, M. (2018). Monitoring Viability and Sustainability in Healthcare Organizations. Sustainability 10, 3548. https://doi.org/10.3390/su10103548

Scalia, M., Barile, S., Saviano, M., \& Farioli, F. (2018). Governance for sustainability: a triple-helix model, Sustain. Sci., 13, 1235-1244.

Sterman, J. D. (2000). Business Dynamics: Systems thinking and modeling for a complex world. McGraw Hill, New York: NY.

Storbacka, K., Brodie, R. J., Böhmann, T., Maglio, P. P. \& Nenonen, S. (2016). Actor engagement as a microfoundation for value co-creation. Journal of Business Research, 69(8), 3008-3017. https://doi.org/10.1016/j.jbusres.2016.02.034

The United Nations, General Assembly (2005). World Summit Outcome A /RES/60/1. 
Trist, E. (1981). The socio-technical perspective: the evolution of sociotechnical systems as a conceptual framework and as an action research program. Van De Ven, A. H. (Ed), Perspectives on Organization Design \& Behavior; John Wiley Sons: New York, NY, pp. 7-67.

Vargo, S. L., \& Lusch, R. F. (2008). Service-dominant logic: continuing the evolution. Journal of the Academy of marketing Science, 36(1), 1-10. https://doi.org/10.1007/s11747-007-0069-6

Vargo, S. L., \& Lusch, R. F. (2016). Institutions and axioms: an extension and update of service-dominant logic. Journal of the Academy of Marketing Science, 44(1), 5-23. https://doi.org/10.1007/s11747-015-0456-3

Walton, J. (1992). What is a case? Ragin, C. \& Becker, H. S. (Eds), Exploring the foundations of social inquiry. New York: Cambridge University Press.

Wilkinson, I. (2008). Business Relating Business, Edward Elgar, Cheltenham.

World Health Organization (2018). World health statistics 2018: monitoring health for the SDGs, sustainable development goals. Geneva.

Yin, R. K. (2014). Case Study Research: Design and methods (5th ed.). Thousand Oaks, CA: Sage.

\section{Copyrights}

Copyright for this article is retained by the author(s), with first publication rights granted to the journal.

This is an open-access article distributed under the terms and conditions of the Creative Commons Attribution license (http://creativecommons.org/licenses/by/4.0/). 